\title{
Meltblowing: II-linear and nonlinear waves on viscoelastic polymer jets
}

\author{
A. L. Yarin, ${ }^{1,2, a)}$ S. Sinha-Ray, ${ }^{1}$ and B. Pourdeyhimi ${ }^{3}$ \\ ${ }^{1}$ Department of Mechanical and Industrial Engineering, University of Illinois at Chicago, 842 W. Taylor St., \\ Chicago, Illinois 60607-7022, USA \\ ${ }^{2}$ Center for Smart Interfaces, Technische Universität Darmstadt, Petersenstr. 32, 64287 Darmstadt, \\ Germany \\ ${ }^{3} 3427$ The Nonwovens Institute, Box 8301, North Carolina State University, Raleigh, North Carolina 27695- \\ 8301, USA
}

(Received 17 March 2010; accepted 8 May 2010; published online 13 August 2010)

\begin{abstract}
The work is devoted to the theory of meltblown polymer jets. Polymer jets are experiencing strong stretching and flapping being subjected to the pulling action of a high speed surrounding axisymmetric gas jet. The bending perturbations of polymer melt jets are triggered by the surrounding turbulent eddies and enhanced by the distributed lift force acting on the jets. We study first growth of small perturbations in the framework of the linear stability theory. Then, the fully nonlinear case of large-amplitude planar bending perturbations of polymer jet is solved numerically. Both isothermal and nonisothermal cases are considered. The cooling of the surrounding gas jet results in cooling of the polymer jet inside, and to the arrest of the bending perturbation growth due to melt solidification. (C) 2010 American Institute of Physics. [doi:10.1063/1.3457893]
\end{abstract}

\section{INTRODUCTION}

Meltblowing of polymer jets is the main process to form various nonwovens. In this process polymer jets are issued into coaxial high speed gas jets. A review of works devoted to the physics of meltblowing in our first paper in this series ${ }^{1}$ and our own results there can be summarized as following. Polymer jet stretching in meltblowing results not only from direct action of aerodynamic drag force but also due to the amplification of the bending perturbations triggered by turbulent eddies in gas and growing due to the distributed lift force. Certain experimental aspects of meltblowing have already been revealed in the literature, and some first steps were done in the direction of developing a comprehensive theory of the process. However, several key elements of such a theory are still lacking. Namely, the whole spectrum of the aerodynamic forces acting on polymer jets in meltblowing is not fully accounted for, and the true rheological behavior of polymer melts, their viscoelasticity, has never been included. The present work aims at closing these gaps. It adopts several findings of our first paper $^{1}$ regarding the aerodynamic interactions revealed in the model situation of threadline blowing, and also incorporates viscoelasticity of polymer jet. The approach used in the present work is based on the quasione-dimensional equations of free liquid jets - the technique which had already been successfully applied to the description of bending perturbations of polymer liquid jets moving with high speed in air or in the electric field in electrospinning. ${ }^{2-6}$

Section II describes the unperturbed flow in polymer viscoelastic jets in meltblowing, while Sec. III covers the linear stability theory of meltblown polymer jets with small bending perturbations. Section IV is devoted to the governing equations in the case of the fully nonlinear, large-amplitude perturbations for the isothermal blowing. Their generaliza-

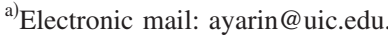

tion on the nonisothermal blowing is given in Sec. V. The numerical solutions of the nonlinear equations and discussion are presented in Sec. VI. Conclusions are drawn in Sec. VII.

\section{UNPERTURBED STRAIGHT POLYMERIC VISCOELASTIC LIQUID JET IN PARALLEL HIGH- SPEED GAS FLOW}

In the case of polymeric liquid jet stretched by surrounding parallel high speed gas jet, flow in the former should be calculated in distinction from the case of solid flexible threadline. ${ }^{1}$ Steady-state flow in an unperturbed straight polymer jet is governed by the following quasi-onedimensional continuity and momentum balance equations ${ }^{2}$

$$
\begin{aligned}
& \frac{\mathrm{dfV}_{\tau}}{\mathrm{dx}}=0, \quad \mathrm{f}=\pi \mathrm{a}^{2}, \\
& \rho \frac{\mathrm{dfV}_{\tau}^{2}}{\mathrm{dx}}=\frac{\mathrm{d} \sigma_{\mathrm{xx}} \mathrm{f}}{\mathrm{dx}}+\mathrm{q}_{\tau},
\end{aligned}
$$

where $\mathrm{f}(\mathrm{x})$ and $\mathrm{a}(\mathrm{x})$ are the cross-sectional area and radius, respectively, and $\mathrm{V}_{\tau}(\mathrm{x})$ is the unperturbed absolute axial velocity of the polymeric liquid in the jet. In Eq. (2) surface tension and gravity effects are neglected as insignificant compared to the dominating inertial ones and internal (rheological) stresses ( $\sigma_{\mathrm{xx}}$ is the longitudinal stress) as well as the aerodynamic drag $\mathrm{q}_{\tau}$ (per unit jet length). As in Ref. 1, the effect of turbulent pulsations in gas is considered to be localized at the "initial" cross-section where they are assumed to impose bending perturbations (in the perturbed case considered in the following sections).

The stretching aerodynamic drag force $\mathrm{q}_{\tau}$ depends on the relative velocity between the gas stream and polymer jet $\left(\mathrm{U}_{\mathrm{g}}-\mathrm{V}_{\tau}\right)$. Therefore, similarly to Ref. 1, the following expression is used in the present case to calculate the local value of the drag force $\mathrm{q}_{\tau}(\mathrm{x})$ : 


$$
\mathrm{q}_{\tau}=0.65 \pi \mathrm{a} \rho_{\mathrm{g}}\left(\mathrm{U}_{\mathrm{g}}-\mathrm{V}_{\tau}\right)^{2}\left[\frac{2\left(\mathrm{U}_{\mathrm{g}}-\mathrm{V}_{\tau}\right) \mathrm{a}}{\nu_{\mathrm{g}}}\right]^{-0.81},
$$

where a is the cross-sectional radius, $\rho_{\mathrm{g}}$ and $\nu_{\mathrm{g}}$ are the gas density and kinematic viscosity, respectively.

Equation (1) is readily integrated, which yields

$$
\pi \mathrm{a}^{2} \mathrm{~V}_{\tau}=\pi \mathrm{a}_{0}^{2} \mathrm{~V}_{\tau 0},
$$

where subscript zero designates the cross-sectional radius and longitudinal velocity values at the "initial" cross-section. This expression allows one to exclude the cross-sectional radius from the consideration, as is done below.

In thin liquid jets the normal stress in the cross-section can be always presented as a difference between the normal and radial deviatoric stresses, $\tau_{\mathrm{xx}}$ and $\tau_{\mathrm{yy}}$, respectively, i.e., as $^{2} \sigma_{\mathrm{xx}}=\tau_{\mathrm{xx}}-\tau_{\mathrm{yy}}$. The deviatoric stresses should be related to the flow kinematics via a rheological constitutive equation (RCE). For polymeric liquids experiencing strong uniaxial stretching as, for example, in meltblowing, an appropriate RCE is the viscoelastic upper-convected Maxwell model ${ }^{7}$ (UCM), which is substantiated by direct statistical consideration of macromolecular stretching and the corresponding entropic elasticity. ${ }^{2}$ In the present case, the RCE of the Maxwell model reduces to the following axial and radial (lateral) projections:

$$
\begin{aligned}
& \mathrm{V}_{\tau} \frac{\mathrm{d} \tau_{\mathrm{xx}}}{\mathrm{dx}}=2 \frac{\mathrm{dV}_{\tau}}{\mathrm{dx}} \tau_{\mathrm{xx}}+\frac{2 \mu}{\theta} \frac{\mathrm{dV}_{\tau}}{\mathrm{dx}}-\frac{\tau_{\mathrm{xx}}}{\theta}, \\
& \mathrm{V}_{\tau} \frac{\mathrm{d} \tau_{\mathrm{yy}}}{\mathrm{dx}}=-\frac{\mathrm{dV}_{\tau}}{\mathrm{dx}} \tau_{\mathrm{yy}}-\frac{\mu}{\theta} \frac{\mathrm{dV}_{\tau}}{\mathrm{dx}}-\frac{\tau_{\mathrm{yy}}}{\theta},
\end{aligned}
$$

where $\mu$ and $\theta$ are the liquid viscosity and relaxation time, respectively.

Combining Eqs. (2)-(6), we can transform them to the following system of dimensionless equations

$$
\begin{aligned}
& \frac{\mathrm{dV}_{\tau}}{\mathrm{dx}}=\frac{\left[-\mathrm{E}\left(\tau_{\mathrm{xx}}-\tau_{\mathrm{yy}}\right) /\left(\mathrm{DeV}_{\tau}^{2}\right)+\mathrm{q}_{\tau}\right]}{\left[1-\mathrm{E}\left(\tau_{\mathrm{xx}}+2 \tau_{\mathrm{yy}}+3\right) / \mathrm{V}_{\tau}^{2}\right]}, \\
& \frac{\mathrm{d} \tau_{\mathrm{xx}}}{\mathrm{dx}}=\frac{1}{\mathrm{~V}_{\tau}}\left(2 \frac{\mathrm{dV}_{\tau}}{\mathrm{dx}} \tau_{\mathrm{xx}}+2 \frac{\mathrm{dV}_{\tau}}{\mathrm{dx}}-\frac{\tau_{\mathrm{xx}}}{\mathrm{De}}\right), \\
& \frac{\mathrm{d} \tau_{\mathrm{yy}}}{\mathrm{dx}}=\frac{1}{\mathrm{~V}_{\tau}}\left(-\frac{\mathrm{dV}_{\tau}}{\mathrm{dx}} \tau_{\mathrm{yy}}-\frac{\mathrm{dV}_{\tau}}{\mathrm{dx}}-\frac{\tau_{\mathrm{yy}}}{\mathrm{De}}\right),
\end{aligned}
$$

where

$$
\mathrm{q}_{\tau}=0.65 \mathrm{R} \ell / \mathrm{V}_{\tau}^{1 / 2}\left(\mathrm{U}_{\mathrm{g}}-\mathrm{V}_{\tau}\right)^{2}\left[\operatorname{Re}\left(\mathrm{U}_{\mathrm{g}}-\mathrm{V}_{\tau}\right) / \mathrm{V}_{\tau}^{1 / 2}\right]^{-0.81}
$$

The equations are rendered dimensionless by the following scales: $\mathrm{V}_{\tau 0}$ for $\mathrm{V}_{\tau}$ and $\mathrm{U}_{\mathrm{g}}$, the distance between the "initial" cross-section and deposition screen $\mathrm{L}$ for $\mathrm{x}, \mathrm{a}_{0}$ for $\mathrm{a}, \mu / \theta$ for $\tau_{\mathrm{xx}}$ and $\tau_{\mathrm{yy}}$, and further on, $\mathrm{L} / \mathrm{V}_{\tau 0}$ for time t. The primary dimensionless groups involved in Eqs. (7)-(10) are given by

$$
\mathrm{R}=\frac{\rho_{\mathrm{g}}}{\rho}, \quad \ell=\frac{\mathrm{L}}{\mathrm{a}_{0}}, \quad \mathrm{Re}=\frac{2 \mathrm{~V}_{\tau 0} \mathrm{a}_{0}}{\nu_{\mathrm{g}}}, \quad \mathrm{De}=\frac{\theta \mathrm{V}_{\tau 0}}{\mathrm{~L}},
$$

with Re and De being the Reynolds and Deborah numbers, respectively; the secondary dimensionless groups are

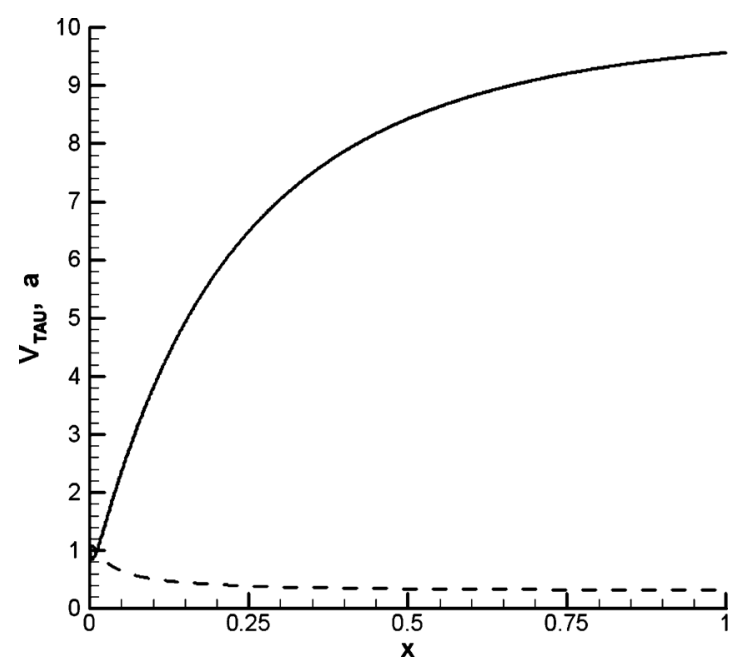

FIG. 1. The unperturbed distributions of the longitudinal velocity (solid line) and cross-sectional radius (dashed line) along polymer jet stretched by high speed gas jet.

$$
\mathrm{E}=\frac{2 \mathrm{R}}{\operatorname{De} \ell \operatorname{Re} \mathrm{M}}, \quad \mathrm{M}=\frac{\mu_{\mathrm{g}}}{\mu} .
$$

In Eq. (12) $\mu_{\mathrm{g}}$ denotes gas viscosity.

The system of three ordinary differential Eqs. (7)-(9) is subjected to the following dimensional conditions at the "initial" cross-section of the polymer jet:

$$
\mathrm{x}=0: \mathrm{V}_{\tau}=1, \quad \tau_{\mathrm{xx}}=\tau_{\mathrm{xx} 0}, \quad \tau_{\mathrm{yy}}=0 .
$$

The fact that all boundary conditions for Eqs. (7)-(9) can be imposed at $\mathrm{x}=0$ stems from the hyperbolicity of this system of equations, which holds if the dimensional initial velocity $\mathrm{V}_{\tau 0}$ is larger than the dimensional speed of the "elastic sound",2,8 $\left(\sigma_{\mathrm{xx}} / \rho\right)^{1 / 2}$. Accounting for Eq. (13), the latter corresponds to the following dimensionless condition:

$$
1>\mathrm{E} \tau_{\mathrm{xx} 0} .
$$

This means that even though polymeric liquids can develop rather significant longitudinal deviatoric stresses in flow inside the die and carry a significant part of it as $\tau_{\mathrm{xx} 0}$ to the "initial" cross-section, ${ }^{10}$ the convective effects in the polymeric jet are initially stronger than propagation of the "elastic sound." Therefore, the information in such a jet is convected downstream, even though the "elastic sound" can propagate not only down- but also upstream (i.e., against the flow, but swept by it). In such cases all boundary conditions are imposed at the beginning of the polymer jet as in Eq. (13).

The system of Eqs. (7)-(9) subjected to the conditions (13) was solved numerically using the Kutta-Merson method.

The solution of Eqs. (7)-(9) for the unperturbed jet is illustrated in Figs. 1-3 for the following values of the parameters: $\mathrm{M}=0.001, \mathrm{R}=0.00122, \ell=83000, \mathrm{De}=0.01$, and $\mathrm{Re}$ $=40$, the dimensionless velocity of the gas flow assumed to be constant in the present case is $\mathrm{U}_{\mathrm{g}}=\mathrm{U}_{\mathrm{g}}(0)=10, \tau_{\mathrm{xx} 0}=10^{4}$, $H_{0 \omega}=0.01$, and the dimensionless perturbation frequency $\Omega$ $=\omega \mathrm{L} / \mathrm{V}_{\tau 0}=1500$. These values of the dimensionless groups correspond to plausible values of the physical parameters 

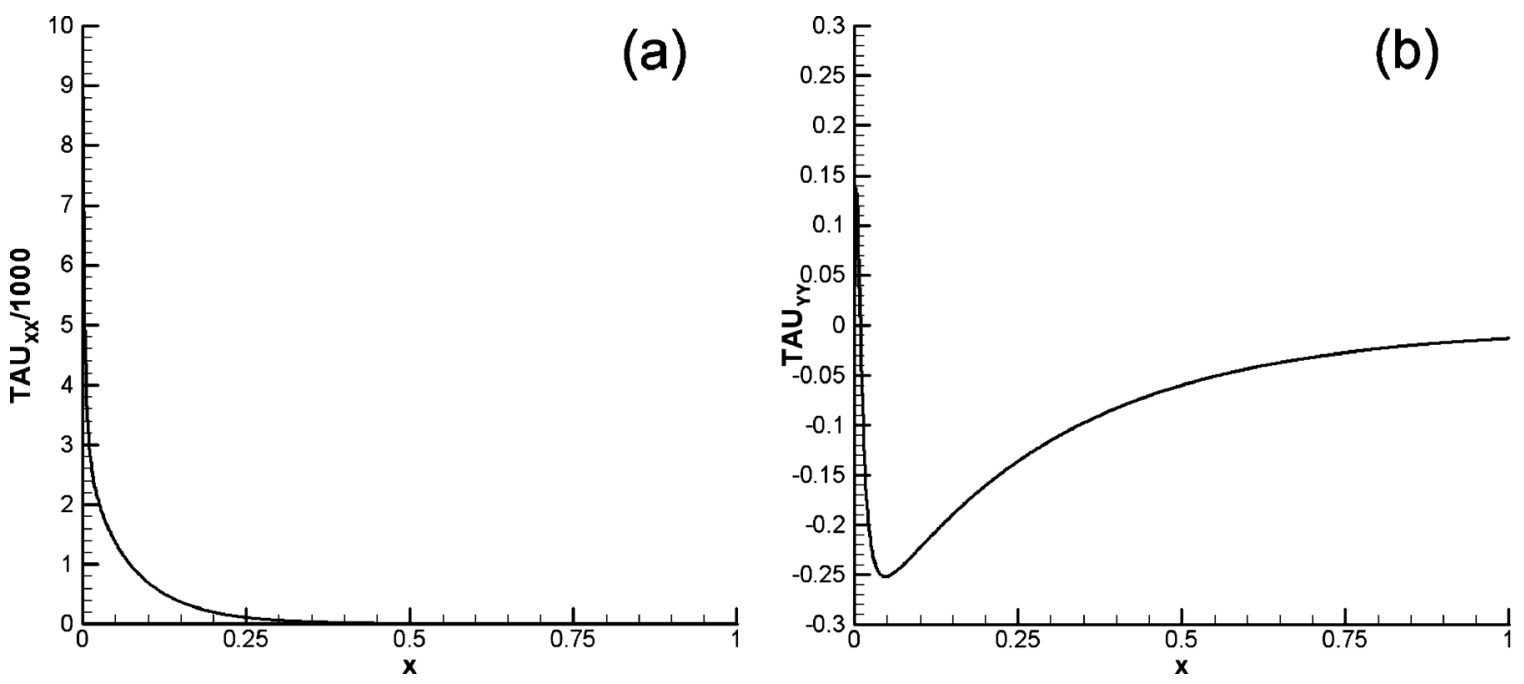

FIG. 2. The unperturbed distributions of the longitudinal (a), and lateral (b) deviatoric stresses ( $\tau_{\mathrm{xx}}$ and $\tau_{\mathrm{yy}}$, respectively) along polymer jet stretched by high speed gas jet.

partially taken from Ref. 11: $a_{0}=3 \times 10^{-3} \mathrm{~cm}, \mathrm{~L}=250 \mathrm{~cm}$, $\rho_{\mathrm{g}}=1.22 \times 10^{-3} \mathrm{~g} / \mathrm{cm}^{3}, \nu_{\mathrm{g}}=0.15 \mathrm{~cm}^{2} / \mathrm{s}, \mathrm{V}_{\tau 0}=10^{3} \mathrm{~cm} / \mathrm{s}$, the dimensional $\mathrm{U}_{\mathrm{g}}(0)=10^{4} \mathrm{~cm} / \mathrm{s}, \theta=0.25 \times 10^{-2} \mathrm{~s}$, and $\omega=6$ $\times 10^{3} \mathrm{~Hz}$.

Figure 1 depicts the unperturbed longitudinal velocity $\mathrm{V}_{\tau}(\mathrm{x})$ and radius $\mathrm{a}(\mathrm{x})$ distributions, and Figs. 2(a) and 2(b)the unperturbed distributions of the longitudinal and lateral deviatoric stresses, $\tau_{\mathrm{xx}}(\mathrm{x})$ and $\tau_{\mathrm{yy}}(\mathrm{x})$, respectively. It is seen that the polymer jet is gradually accelerated by the aerodynamic drag imposed by the gas stream, and simultaneously thins (Fig. 1). The longitudinal deviatoric stress $\tau_{\mathrm{xx}}$, which is rather high at the die exit due to the prior strong stretching in the die channel, decreases along the jet because the elongation rate due to the gas flow there is insufficiently high to overcome the viscoelastic relaxation [the so-called, weak flow; cf. Fig. 2(a)]. Comparison of Figs. 2(a) and 2(b) shows that the lateral deviatoric stress $\tau_{\mathrm{yy}}$ is negligibly small compared to the lateral one, $\tau_{\mathrm{xx}}$, as expected in the uniaxial elongational flows.

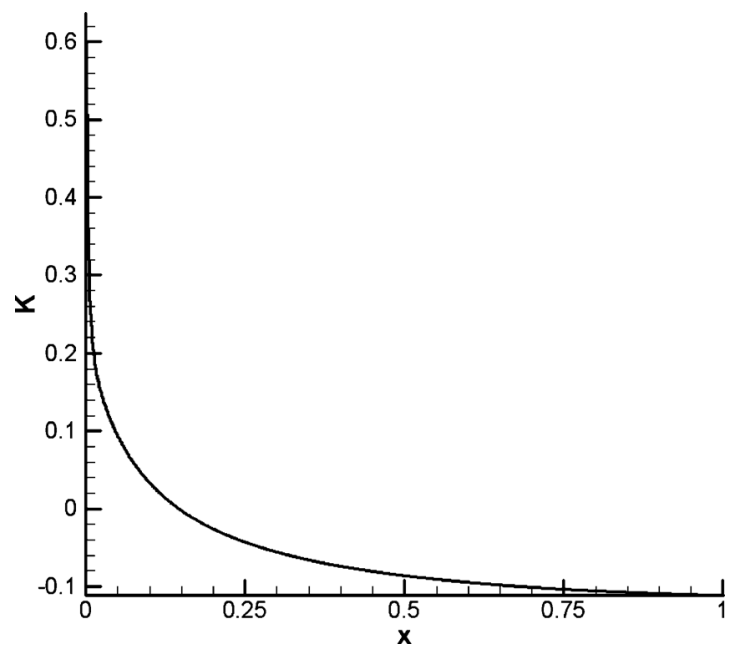

FIG. 3. Distribution of $\mathrm{K}(\mathrm{x})$.

\section{SMALL PERTURBATIONS OF POLYMERIC VISCOELASTIC LIQUID JET IN PARALLEL HIGH- SPEED GAS FLOW}

Bending perturbations of polymer jets stretched by high speed gas jet will be studied using the quasi-one-dimensional equations of the dynamics of free liquid jets. ${ }^{2}$ In the momentless approximation (neglecting the bending stiffness) and assuming small bending perturbations (linearizing), one can reduce Eqs. (4.19) on p. 49 in Ref. 2 to the normal projection of the momentum balance equation in the following dimensional form:

$$
\frac{\partial^{2} \mathrm{H}}{\partial \mathrm{t}^{2}}+2 \mathrm{~V}_{\tau} \frac{\partial^{2} \mathrm{H}}{\partial \mathrm{x} \partial \mathrm{t}}+\left[\mathrm{V}_{\tau}^{2}+\frac{\rho_{\mathrm{g}}\left(\mathrm{U}_{\mathrm{g}}-\mathrm{V}_{\tau}\right)^{2}-\sigma_{\mathrm{xx}}}{\rho}\right] \frac{\partial^{2} \mathrm{H}}{\partial \mathrm{x}^{2}}=0 .
$$

Rendering this equation dimensionless using the scales listed above in Sec. II, the following dimensionless equation is obtained:

$$
\frac{\partial^{2} \mathrm{H}}{\partial \mathrm{t}^{2}}+2 \mathrm{~V}_{\tau} \frac{\partial^{2} \mathrm{H}}{\partial \mathrm{x} \partial \mathrm{t}}+\left[\mathrm{V}_{\tau}^{2}+\mathrm{R}\left(\mathrm{U}_{\mathrm{g}}-\mathrm{V}_{\tau}\right)^{2}-\mathrm{E} \sigma_{\mathrm{xx}}\right] \frac{\partial^{2} \mathrm{H}}{\partial \mathrm{x}^{2}}=0
$$

where $\mathrm{L}$ is also used as a scale for the perturbation amplitude H. Equations (15) and (16) are kindred to Eq. (6) in Ref. 1 for the bending perturbations of a solid flexible threadline.

It is emphasized that in the linear approximation, perturbations of the longitudinal flow do not affect small bending perturbations, i.e., the latter are completely uncoupled from the former ones, since the coupling could happen only via nonlinear terms. Therefore, in Eq. (16) the factors multiplying the derivatives in the second and third terms on the left depend on the unperturbed distributions of $\mathrm{V}_{\tau}(\mathrm{x})$ and $\sigma_{\mathrm{xx}}(\mathrm{x})=\tau_{\mathrm{xx}}(\mathrm{x})-\tau_{\mathrm{yy}}(\mathrm{x})$, which are found from Eqs. (7)-(9).

The general solution of Eq. (16) can be found using the characteristics 


$$
\frac{\mathrm{dx}}{\mathrm{dt}}=\mathrm{V}_{\tau} \pm\left[\mathrm{E} \sigma_{\mathrm{xx}}-\mathrm{R}\left(\mathrm{U}_{\mathrm{g}}-\mathrm{V}_{\tau}\right)^{2}\right]^{1 / 2}
$$

Equation (16) is hyperbolic if $\mathrm{E} \sigma_{\mathrm{xx}}-\mathrm{R}\left(\mathrm{U}_{\mathrm{g}}-\mathrm{V}_{\tau}\right)^{2}>0$ and the characteristics are real, and elliptic if $\mathrm{E} \sigma_{\mathrm{xx}}-\mathrm{R}\left(\mathrm{U}_{\mathrm{g}}-\mathrm{V}_{\tau}\right)^{2}<0$ and the characteristics are complex. This means that if at $\mathrm{x}$ $=0$, the inequality $\mathrm{E} \tau_{\mathrm{xx} 0}>\mathrm{R}\left[\mathrm{U}_{\mathrm{g}}(0)-1\right]^{2}$ holds, the initial part of the jet is "hyperbolic." Given Eq. (14), the conditions that the initial part of the jet is "hyperbolic" in both unperturbed and perturbed states are

$$
1>\mathrm{E} \tau_{\mathrm{xx} 0}>\mathrm{R}\left[\mathrm{U}_{\mathrm{g}}(0)-1\right]^{2} .
$$

The transition cross-section $\mathrm{x}=\mathrm{x}_{*}$ is found from the following equation:

$$
\mathrm{K}(\mathrm{x})=\mathrm{E} \sigma_{\mathrm{xx}}(\mathrm{x})-\mathrm{R}\left[\mathrm{U}_{\mathrm{g}}(\mathrm{x})-\mathrm{V}_{\tau}(\mathrm{x})\right]^{2}=0 .
$$

The general solution of Eq. (16) is given by

$$
\begin{aligned}
\mathrm{H}(\mathrm{x}, \mathrm{t})= & \Phi\left[\int_{0}^{\mathrm{x}} \frac{\mathrm{dx}}{\mathrm{V}_{\tau}+\sqrt{\mathrm{E} \sigma_{\mathrm{xx}}-\mathrm{R}\left(\mathrm{U}_{\mathrm{g}}-\mathrm{V}_{\tau}\right)^{2}}}-\mathrm{t}\right] \\
& +\mathrm{F}\left[\int_{0}^{\mathrm{x}} \frac{\mathrm{dx}}{\mathrm{V}_{\tau}-\sqrt{\mathrm{E} \sigma_{\mathrm{xx}}-\mathrm{R}\left(\mathrm{U}_{\mathrm{g}}-\mathrm{V}_{\tau}\right)^{2}}}-\mathrm{t}\right]
\end{aligned}
$$

where $\Phi(\cdot)$ and $\mathrm{F}(\cdot)$ are arbitrary functions.

Assume that the inequalities (18) hold. Then, the initial part of the polymeric jet $0 \leq \mathrm{x} \leq \mathrm{x}_{*}$ is "hyperbolic," whereas the following part $\mathrm{x}_{*} \leq \mathrm{x} \leq 1$ "elliptic."

Here again, as in the case of the threadline, ${ }^{1}$ we apply the conditions for the perturbation wave at the "initial" crosssection of the polymer jet in the following form:

$$
\left.\mathrm{H}\right|_{\mathrm{x}=0}=\mathrm{H}_{0 \omega} \exp (\mathrm{i} \omega \mathrm{t}), \quad \partial \mathrm{H} /\left.\partial \mathrm{x}\right|_{\mathrm{x}=0}=0
$$

which corresponds to the overall effect of the turbulent pulsations being combined there.

Then, we can find the functions $\Phi(\cdot)$ and $\mathrm{F}(\cdot)$ and reduce Eq. (20) to the following solution for the "hyperbolic" part at $0 \leq \mathrm{x} \leq \mathrm{x}_{*}$

$$
\begin{aligned}
\mathrm{H}(\mathrm{x}, \mathrm{t})= & \frac{\mathrm{H}_{0 \omega}}{1-\delta} \exp (\mathrm{i} \omega \mathrm{t})\left\{-\delta \exp \left[-\mathrm{i} \omega \mathrm{I}_{1}(\mathrm{x})\right]\right. \\
& \left.+\exp \left[-\mathrm{i} \omega \mathrm{I}_{2}(\mathrm{x})\right]\right\}
\end{aligned}
$$

where the two real functions $\mathrm{I}_{1}(\mathrm{x})$ and $\mathrm{I}_{2}(\mathrm{x})$ are given by

$$
\begin{aligned}
& \mathrm{I}_{1}(\mathrm{x})=\int_{0}^{\mathrm{x}} \frac{\mathrm{dx}}{\mathrm{V}_{\tau}(\mathrm{x})+\sqrt{\mathrm{E} \sigma_{\mathrm{xx}}(\mathrm{x})-\mathrm{R}\left[\mathrm{U}_{\mathrm{g}}(\mathrm{x})-\mathrm{V}_{\tau}(\mathrm{x})\right]^{2}}}, \\
& \mathrm{I}_{2}(\mathrm{x})=\int_{0}^{\mathrm{x}} \frac{\mathrm{dx}}{\mathrm{V}_{\tau}(\mathrm{x})-\sqrt{\mathrm{E} \sigma_{\mathrm{xx}}(\mathrm{x})-\mathrm{R}\left[\mathrm{U}_{\mathrm{g}}(\mathrm{x})-\mathrm{V}_{\tau}(\mathrm{x})\right]^{2}}},
\end{aligned}
$$

and

$$
\delta=\left.\frac{\mathrm{dI}_{2} / \mathrm{dx}}{\mathrm{dI}_{1} / \mathrm{dx}}\right|_{\mathrm{x}=0} .
$$

The corresponding solution for the "elliptic" (in regards to bending perturbations) part of the polymer jet at $\mathrm{x}_{*} \leq \mathrm{x} \leq 1$ is also obtained from the general solution (20). After it is matched to the "hyperbolic" solution at the transition point $\mathrm{x}=\mathrm{x}_{*}$, it reads

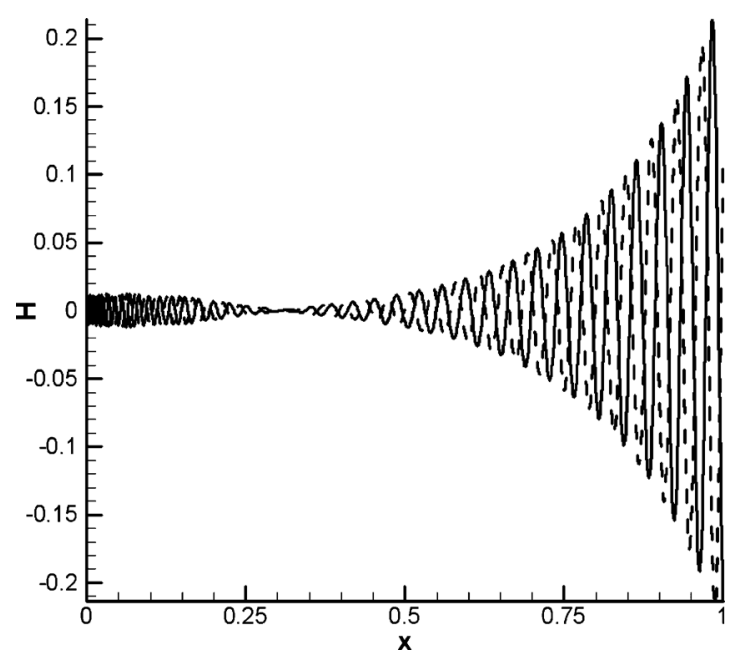

FIG. 4. Two snapshots (one shown by solid line, another one by the dashed one) of the predicted traveling wave of the bending perturbations of polymer jet enhanced by the distributed aerodynamic lift force.

$$
\begin{aligned}
\mathrm{H}(\mathrm{x}, \mathrm{t})= & \frac{\mathrm{H}_{0 \omega}}{1-\delta} \exp \left\{\mathrm{i} \omega\left[\mathrm{t}-\mathrm{J}_{1}(\mathrm{x})\right]\right\} \\
& \times\left\{-\delta \exp \left[-\mathrm{i} \omega \mathrm{I}_{1}\left(\mathrm{x}_{*}\right)\right] \exp \left[-\omega \mathrm{J}_{2}(\mathrm{x})\right]\right. \\
& \left.+\exp \left[-\mathrm{i} \omega \mathrm{I}_{2}\left(\mathrm{x}_{*}\right)\right] \exp \left[\omega \mathrm{J}_{2}(\mathrm{x})\right]\right\} .
\end{aligned}
$$

In Eq. (26) the two additional real functions $\mathrm{J}_{1}(\mathrm{x})$ and $\mathrm{J}_{2}(\mathrm{x})$ are defined as

$$
\mathrm{J}_{1}(\mathrm{x})=\int_{\mathrm{x} *}^{\mathrm{x}} \frac{\mathrm{V}_{\tau}(\mathrm{x})}{\mathrm{V}_{\tau}^{2}(\mathrm{x})+\mathrm{R}\left[\mathrm{U}_{\mathrm{g}}(\mathrm{x})-\mathrm{V}_{\tau}(\mathrm{x})\right]^{2}-\mathrm{E} \sigma_{\mathrm{xx}}(\mathrm{x})} \mathrm{dx}
$$

$$
\mathrm{J}_{2}(\mathrm{x})=\int_{\mathrm{x} *}^{\mathrm{x}} \frac{\sqrt{\mathrm{R}\left[\mathrm{U}_{\mathrm{g}}(\mathrm{x})-\mathrm{V}_{\tau}(\mathrm{x})\right]^{2}-\mathrm{E} \sigma_{\mathrm{xx}}(\mathrm{x})}}{\mathrm{V}_{\tau}^{2}(\mathrm{x})+\mathrm{R}\left[\mathrm{U}_{\mathrm{g}}(\mathrm{x})-\mathrm{V}_{\tau}(\mathrm{x})\right]^{2}-\mathrm{E} \sigma_{\mathrm{xx}}(\mathrm{x})} \mathrm{dx}
$$

It is emphasized that the dimensional gas stream velocity at the outer boundary of the boundary layer near the liquid jet surface, $\mathrm{U}_{\mathrm{g}}(\mathrm{x})$, can be evaluated using the theory of the axisymmetric turbulent gas jets ${ }^{12,13}$ as

$$
\mathrm{U}_{\mathrm{g}}(\mathrm{x})=\mathrm{U}_{\mathrm{g}}(0) \frac{2.4 \mathrm{~d}_{0}}{\mathrm{x}+2.4 \mathrm{~d}_{0}},
$$

where $\mathrm{d}_{0} \approx 2 \mathrm{a}_{0}$ is the diameter of the coaxial gas jet nozzle, and $2.4 \mathrm{~d}_{0}$ is the polar distance of the jet.

The corresponding dimensionless expression becomes

$$
\mathrm{U}_{\mathrm{g}}(\mathrm{x})=\mathrm{U}_{\mathrm{g}}(0) \frac{4.8 / \ell}{\mathrm{x}+4.8 / \ell},
$$

where $\mathrm{U}_{\mathrm{g}}(\mathrm{x})$ and $\mathrm{U}_{\mathrm{g}}(0)$ are rendered dimensionless by $\mathrm{V}_{\tau 0}$.

Figure 3 depicts the function $\mathrm{K}(\mathrm{x})$ of Eq. (19), which is obtained from the solution for the unperturbed straight jet in Sec. II. It is seen that $\mathrm{K}(\mathrm{x})=0$ at $\mathrm{x}=\mathrm{x}_{*}=0.146$. This means that at $0 \leq \mathrm{x} \leq 0.146$ bending perturbations are "hyperbolic," whereas at $0.146 \leq \mathrm{x} \leq 1$ they are "elliptic." Two predicted snapshots of the bending jet configurations corresponding to two different time moments are shown in Fig. 4. It is seen 
that in the "hyperbolic" part described by Eq. (22) the traveling perturbation wave has the amplitude of the order of $\mathrm{H}_{0 \omega}$. After the transition to the "elliptic" part, the amplitude of the traveling perturbation wave described by Eq. (26) even decreases, but after the bottleneck seen in Fig. 4 at about $\mathrm{x}=0.35$, the perturbation amplitude rapidly increases, as is expected for an elliptic problem solved as an initialvalue problem. That is the area where the perturbed jet will be drastically stretched and thinned. An accurate description of such thinning can be achieved only in the framework of a fully nonlinear description in the following section.

The pattern of the perturbation waves predicted for meltblowing in Fig. 4 is rather peculiar. It shows that the initial part of the jet attached to the die can be almost straight, since it is stabilized by sufficiently large longitudinal stresses generated in the die and still not fully vanished there. On the other hand, when relaxation of the longitudinal stresses significantly reduces their level, bending perturbations grow and begin to release the stored energy delivered by the initial perturbations (turbulent pulsations) and are also enhanced by the distributed lift force. A renewed significant liquid stretching is expected because of strong bending, which will be also accompanied by drastic thinning of polymer jet. This behavior is quite similar to the patterns characteristic of electrospun polymer jets. In the latter case the bending force related to the Coulombic repulsion is formally similar to the distributed aerodynamic lift force here (both are proportional to the local curvature of the jet axis). ${ }^{5}$ The presence of significant longitudinal viscoelastic stresses in the initial part of electrospun jets stabilizes them and they stay almost straight. Later on, the stresses fade due to viscoelastic relaxation and strong bending begins. ${ }^{4-6,10}$ Correspondingly, meltblown jets can stay initially almost straight due to stabilization by high longitudinal stress. Only after it fades due to the dominant relaxation, a vigorous bending leading to jet elongation and thinning begins.

\section{NONLINEAR BEHAVIOR: LARGE-AMPLITUDE BENDING PERTURBATIONS IN THE ISOTHERMAL CASE}

In the quasi-one-dimensional theory of liquid jets two types of approaches to describing jet bending (with and without accounting for the bending stiffness) are available. ${ }^{2}$ In the momentless approximation bending stiffness of very thin liquid jets is neglected compared to the other internal forces affecting bending, since it depends on the cross-sectional jet radius as $\mathrm{a}^{4}$, while the other forces as $\mathrm{a}^{2}$ (which is much larger as a tends to zero). ${ }^{2}$ In the present section we adopt the momentless approximation and neglect the shearing force in the jet cross-section and the whole moment-of-momentum equation determining it. As a result, the quasi-onedimensional equations of the jet dynamics reduce to the autonomous continuity and momentum balance equations in the following form [Eqs. (4.18) on p. 48 in Ref. 2]

$$
\frac{\partial \lambda \mathrm{f}}{\partial \mathrm{t}}+\frac{\partial \mathrm{fW}}{\partial \mathrm{s}}=0,
$$

$$
\frac{\partial \lambda \mathrm{f} \mathbf{V}}{\partial \mathrm{t}}+\frac{\partial \mathrm{fWV}}{\partial \mathrm{s}}=\frac{1}{\rho} \frac{\partial \mathrm{P} \boldsymbol{\tau}}{\partial \mathrm{s}}+\lambda \mathrm{fg}+\frac{\lambda}{\rho} \mathbf{q}_{\mathrm{total}} .
$$

In Eqs. (31) and (32) $t$ is time, $s$ is an arbitrary parameter (coordinate) reckoned along the jet axis, $\mathrm{f}(\mathrm{s}, \mathrm{t})=\pi \mathrm{a}^{2}$ is the cross-sectional area [the cross-section is assumed to stay circular even in bending jets-a valid approximation according to Ref. 2; a(s,t) denotes its radius], $\mathrm{W}$ is the liquid velocity along the jet relative to a cross-section with a certain value of $\mathrm{s}$, the stretching factor $\lambda=|\partial \boldsymbol{R} / \partial \mathrm{s}|$, where $\boldsymbol{R}(\mathrm{s}, \mathrm{t})$ is the position vector of the jet axis, $V(\mathrm{~s}, \mathrm{t})$ is the absolute velocity in the jet, $\rho$ is liquid density, $\mathrm{P}(\mathrm{s}, \mathrm{t})$ is the magnitude of the longitudinal internal force of viscoelastic origin in the jet cross-section, $\boldsymbol{\tau}$ is the unit tangent vector of the jet axis, $\boldsymbol{g}$ is gravity acceleration, and $\boldsymbol{q}_{\text {total }}$ is the overall aerodynamic force imposed on unit jet length by the surrounding gas. Boldfaced characters here and hereinafter denote vectors.

Let $\mathrm{s}$ be a Lagrangian parameter of liquid elements in the jet (e.g., their initial Cartesian coordinate along the blowing direction). Then, $\mathrm{W}=0$, since the particles keep their Lagrangian coordinate unchanged, and Eq. (31) is integrated to yield

$$
\lambda \mathrm{a}^{2}=\lambda_{0} \mathrm{a}_{0}^{2},
$$

where subscript zero denotes the initial values.

Consider for example two-dimensional bending perturbations of the jet (the fully three-dimensional bending can be considered similarly along the same lines ${ }^{2}$ ). Then, accounting for Eq. (33), the two projections of Eq. (32) on the directions of the local tangent $\boldsymbol{\tau}$ and unit normal $\boldsymbol{n}$ to the jet axis read

$$
\begin{aligned}
& \frac{\partial \mathrm{V}_{\tau}}{\partial \mathrm{t}}=\mathrm{V}_{\mathrm{n}}\left(\frac{1}{\lambda} \frac{\partial \mathrm{V}_{\mathrm{n}}}{\partial \mathrm{s}}+\mathrm{kV}_{\tau}\right)+\frac{1}{\rho \mathrm{f} \lambda} \frac{\partial \mathrm{P}}{\partial \mathrm{s}}+\mathrm{g}_{\tau}+\frac{\mathrm{q}_{\text {total }, \tau}}{\rho \mathrm{f}}, \\
& \frac{\partial \mathrm{V}_{\mathrm{n}}}{\partial \mathrm{t}}=-\mathrm{V}_{\tau}\left(\frac{1}{\lambda} \frac{\partial \mathrm{V}_{\mathrm{n}}}{\partial \mathrm{s}}+\mathrm{kV}_{\tau}\right)+\frac{\mathrm{Pk}}{\rho \mathrm{f}}+\mathrm{g}_{\mathrm{n}}+\frac{\mathrm{q}_{\text {total }, \mathrm{n}}}{\rho \mathrm{f}},
\end{aligned}
$$

where $\mathrm{k}$ is the local curvature of the jet axis and subscripts $\tau$ and $\mathrm{n}$ denote vector projections on the local tangent and normal to the jet axis.

In the case of planar bending, the position vector of the jet axis is described as

$$
\boldsymbol{R}=\boldsymbol{i} \xi(\mathrm{s}, \mathrm{t})+\boldsymbol{j} \mathrm{H}(\mathrm{s}, \mathrm{t}),
$$

with $\boldsymbol{i}$ and $\boldsymbol{j}$ being the unit vectors of the directions of blowing and the direction normal to it, respectively, while the geometric parameters $\lambda$ and $\mathrm{k}$ are given by

$$
\begin{aligned}
& \lambda=\left(\xi_{, \mathrm{s}}^{2}+\mathrm{H}_{, \mathrm{s}}^{2}\right)^{1 / 2}, \\
& \mathrm{k}=\frac{\mathrm{H}_{\mathrm{ss}} \xi_{\mathrm{s}}-\xi_{, \mathrm{ss}} \mathrm{H}_{, \mathrm{s}}}{\left(\xi_{, \mathrm{s}}^{2}+\mathrm{H}_{\mathrm{s}}^{2}\right)^{3 / 2}} .
\end{aligned}
$$

The total aerodynamic force is comprised from the distributed longitudinal lift force ${ }^{2,3}$ [a nonlinear analog of the linearized lift force incorporated in Eq. (15)], the distributed drag force associate with gas flow across the jet ${ }^{2,3}$ and the pulling drag force similar to that of Eq. (3). Therefore, 


$$
\begin{aligned}
\boldsymbol{q}_{\text {total }}= & \mathbf{n} \mathrm{q}_{\text {total }, \mathrm{n}}+\boldsymbol{\tau} \mathrm{q}_{\text {total }, \tau}=-\rho_{\mathrm{g}} \mathrm{U}_{\mathrm{g}}^{2} \mathrm{n}\left[\mathrm{f} \frac{\xi_{\mathrm{s}}^{2}\left(\mathrm{H}_{\mathrm{ss}} \xi_{\mathrm{s}}-\xi_{\mathrm{ss}} \mathrm{H}_{, \mathrm{s}}\right)}{\left(\xi_{, \mathrm{s}}^{2}+\mathrm{H}_{\mathrm{s}}^{2}\right)^{5 / 2}}\right. \\
& \left.+\mathrm{a} \frac{\left(\mathrm{H}_{\mathrm{s}} / \xi_{\mathrm{s}}\right)^{2} \operatorname{sign}\left(\mathrm{H}_{\mathrm{s}} / \xi_{\mathrm{s}}\right)}{1+\left(\mathrm{H}_{\mathrm{s}} / \xi_{\mathrm{s}}\right)^{2}}\right]+\pi \mathrm{a} \rho_{\mathrm{g}}\left(\mathrm{U}_{\mathrm{g}} \tau_{\xi}\right. \\
& \left.-\mathrm{V}_{\tau}\right)^{2} 0.65\left[\frac{2 \mathrm{a}\left(\mathrm{U}_{\mathrm{g}} \tau_{\xi}-\mathrm{V}_{\tau}\right)}{\nu_{\mathrm{g}}}\right]^{-0.81} \tau,
\end{aligned}
$$

where $\mathrm{U}_{\mathrm{g}}$ is the magnitude of the absolute local blowing velocity of gas, and $\tau_{\xi}$ corresponds to its projection on the local direction of the polymer jet axis.

In addition, in Eqs. (34) and (35) the projections of the gravity acceleration $\mathrm{g}_{\tau}$ and $\mathrm{g}_{\mathrm{n}}$ are equal to $\mathrm{g}_{\tau}=\mathrm{g} \tau_{\xi}$ and $\mathrm{g}_{\mathrm{n}}$ $=\mathrm{gn}_{\xi}$ with $\mathrm{g}$ being its magnitude and $\mathrm{n}_{\xi}$ the local projection of the unit normal to the jet axis onto the direction of blowing.

The longitudinal internal force of viscoelastic origin in the jet cross-section ${ }^{2} \mathrm{P}=\mathrm{f}\left(\tau_{\tau \tau}-\tau_{\mathrm{nn}}\right)$ where $\tau_{\tau \tau}$ and $\tau_{\mathrm{nn}}$ are the longitudinal and normal deviatoric stresses in the jet crosssection. As usual, in the case of strong stretching (cf. for example, Sec. II), $\tau_{\tau \tau} \gg \tau_{\mathrm{nn}}$ and the latter can be neglected. Then, $\mathrm{P}=\mathrm{f} \tau_{\tau \tau}$ where the constitutive equation for $\tau_{\tau \tau}$ is provided by the viscoelastic ${ }^{7} \mathrm{UCM}$ in the form

$$
\frac{\partial \tau_{\tau \tau}}{\partial \mathrm{t}}=2 \tau_{\tau \tau} \frac{1}{\lambda} \frac{\partial \lambda}{\partial \mathrm{t}}+2 \frac{\mu}{\theta} \frac{1}{\lambda} \frac{\partial \lambda}{\partial \mathrm{t}}-\frac{\tau_{\tau \tau}}{\theta} .
$$

Equations (33)-(35) and (37)-(40) which describe jet dynamics are supplemented by the following kinematic equations which describe the axis shape:

$$
\begin{aligned}
& \frac{\partial \xi}{\partial \mathrm{t}}=\mathrm{V}_{\tau} \mathrm{n}_{\eta}-\mathrm{V}_{\mathrm{n}} \tau_{\eta}, \\
& \frac{\partial \mathrm{H}}{\partial \mathrm{t}}=\mathrm{V}_{\mathrm{n}} \tau_{\xi}-\mathrm{V}_{\tau} \mathrm{n}_{\xi}
\end{aligned}
$$

The projections of the unit vectors associated with the polymer jet axis $\boldsymbol{\tau}$ and $\boldsymbol{n}$ on the directions of the unit vectors $\boldsymbol{i}$ and $j$ associated with the blowing direction and normal to it $(\xi$ and $\mathrm{H})$ are given by the following expressions:

$$
\begin{aligned}
& \tau_{\xi}=\mathrm{n}_{\eta}=\left[1+\left(\mathrm{H}_{\mathrm{s}} / \xi_{\mathrm{s}}\right)^{2}\right]^{-1 / 2}, \\
& \mathrm{n}_{\xi}=-\tau_{\eta}=-\left(\mathrm{H}_{, \mathrm{s}} / \xi_{\mathrm{s}, \mathrm{s}}\right)\left[1+\left(\mathrm{H}_{\mathrm{s}} / \xi_{\mathrm{s}}\right)^{2}\right]^{-1 / 2} .
\end{aligned}
$$

According to the theory of the axisymmetric turbulent gas jets, ${ }^{12,13}$ the gas flow field is given by the following expression:

$$
\mathrm{U}_{\mathrm{g}}(\xi, \mathrm{H})=\mathrm{U}_{\mathrm{g} 0} \varphi(\xi, \mathrm{H}),
$$

where $\mathrm{U}_{\mathrm{g} 0}$ is the gas velocity of the nozzle exit and the dimensionless function $\varphi(\xi, \mathrm{H})$ is given by

$$
\begin{aligned}
\varphi(\xi, \mathrm{H}) & =\frac{4.8 / \ell}{(\xi+4.8 / \ell)} \frac{1}{\left(1+\zeta^{2} / 8\right)^{2}}, \quad \zeta=\zeta(\xi, \mathrm{H}) \\
& =\frac{\mathrm{H}}{0.05(\xi+4.8 / \ell)} .
\end{aligned}
$$

In Eq. (46) $\xi$ and $H$ are rendered dimensionless by L, the distance between the "initial" cross-section and deposition screen, and $\ell$ is given by Eq. (11).

Neglecting secondary terms, the governing equations of the problem (34), (35), and (40)-(42) in the isothermal case can be reduced to the following dimensionless form:

$$
\begin{aligned}
\frac{\partial^{2} \xi}{\partial \mathrm{t}^{2}}= & \frac{2}{\operatorname{Re}} \Phi \frac{\partial^{2} \xi}{\partial \mathrm{s}^{2}}+\frac{1}{\mathrm{Fr}^{2}} \tau_{\xi}+J \ell \frac{\mathrm{q}_{\mathrm{total}, \tau}}{\mathrm{f}}, \\
\frac{\partial^{2} \mathrm{H}}{\partial \mathrm{t}^{2}}= & {\left[\frac{\tau_{\tau \tau}}{\operatorname{Re}}-\mathrm{J} \varphi^{2}(\xi, \mathrm{H})\right] \frac{1}{\lambda^{2}} \frac{\partial^{2} \mathrm{H}}{\partial \mathrm{s}^{2}}+\frac{\mathrm{n}_{\xi}}{\mathrm{Fr}^{2}} } \\
& -\mathrm{J} \ell \frac{\varphi^{2}(\xi, \mathrm{H})}{\pi \mathrm{a}} \frac{\left(\mathrm{H}_{\mathrm{s}} / \xi_{\mathrm{s}}\right)^{2} \operatorname{sign}\left(\mathrm{H}_{\mathrm{s}} / \xi_{\mathrm{s}}\right)}{1+\left(\mathrm{H}_{, \mathrm{s}} / \xi_{\mathrm{s}}\right)^{2}},
\end{aligned}
$$

where $\Phi=\left(\tau_{\tau \tau}+1 / \mathrm{De}\right) \lambda^{-2}$ satisfies the following equation:

$$
\frac{\partial \Phi}{\partial \mathrm{t}}=-\frac{\tau_{\tau \tau}}{\operatorname{De} \lambda^{2}},
$$

In Eq. (47)

$$
\begin{aligned}
\mathrm{q}_{\text {total }, \tau}= & \pi \mathrm{a}\left[\tau_{\xi} \varphi(\xi, \mathrm{H})-\mathrm{V}_{\tau}\right]^{2} 0.65\left\{\operatorname { R e } _ { \mathrm { a } } \mathrm { a } \left[\tau_{\xi} \varphi(\xi, \mathrm{H})\right.\right. \\
& \left.\left.-\mathrm{V}_{\tau}\right]\right\}^{-0.81} .
\end{aligned}
$$

The following scales have been used: $\mathrm{L} / \mathrm{U}_{\mathrm{g} 0}$ for $\mathrm{t}$; $\mathrm{L}$ for $\mathrm{s}, \xi$ and $\mathrm{H} ; \mathrm{L}^{-1}$ for $\mathrm{k} ; \mu \mathrm{U}_{\mathrm{g} 0} / \mathrm{L}$ for $\tau_{\tau \tau}$ and $\Phi ; \mathrm{U}_{\mathrm{g} 0}$ for $\mathrm{U}_{\mathrm{g}}, \mathrm{V}_{\tau}$ and $\mathrm{V}_{\mathrm{n}} ; \mathrm{a}_{0}$ for a (and $\mathrm{a}_{0}^{2}$ for $\mathrm{f}$ ); $\rho_{\mathrm{g}} \mathrm{U}_{\mathrm{g} 0}^{2} \mathrm{a}_{0}$ for $\mathrm{q}_{\text {total }, \tau} ; \mu / \rho$ for the kinematic turbulent eddy viscosity $\nu_{\mathrm{t}}$ (used below; cf. Ref. 1 ). As a result, the following dimensionless groups arise in addition to $\ell=\mathrm{L} / a_{0}$ :

$$
\begin{aligned}
& \operatorname{Re}=\frac{\rho \mathrm{LU}_{\mathrm{g} 0}}{\mu}, \quad \mathrm{J}=\frac{\rho_{\mathrm{g}}}{\rho}, \quad \mathrm{Fr}=\left(\frac{\mathrm{U}_{\mathrm{g} 0}^{2}}{\mathrm{gL}}\right)^{1 / 2}, \\
& \operatorname{Re}_{\mathrm{a}}=\frac{2 \mathrm{a}_{0} \mathrm{U}_{\mathrm{g} 0}}{\nu_{\mathrm{g}}}, \quad \mathrm{De}=\frac{\theta \mathrm{U}_{\mathrm{g} 0}}{\mathrm{~L}},
\end{aligned}
$$

where $\operatorname{Re}$ and $\mathrm{Re}_{\mathrm{a}}$ are the corresponding Reynolds numbers, Fr is the Froude number, and De is the Deborah number.

It is emphasized that the governing quasi-onedimensional equations in the general case of the threedimensional (nonplanar) meltblowing were derived from the vectorial Eqs. (31) and (32) similarly to two-dimensional planar ones, Eqs. (47) and (48). They are not present here for the sake of brevity.

Based on the results in, ${ }^{1}$ we assume that turbulent pulsations in the gas jet impose lateral perturbations at the origin of the polymer melt jet at $\mathrm{s}=\mathrm{s}_{\text {origin }}$. Therefore, similarly to Eq. (11) and using the results of, ${ }^{1}$ the boundary conditions for Eqs. (47) and (48) are given by the following dimensionless expressions:

$$
\left.\xi\right|_{\mathrm{s}=\mathrm{s}_{\text {origin }}}=0,\left.\mathrm{H}\right|_{\mathrm{s}=\mathrm{s}_{\text {origin }}}=\mathrm{H}_{0 \Omega} \exp (\mathrm{i} \Omega \mathrm{t}),
$$

where

$$
\mathrm{H}_{0 \Omega}=\left(0.06 \mathrm{Re}^{1 / 2} / \ell\right)^{1 / 2} / \tau_{\tau \tau 0}^{1 / 4}, \quad \Omega=\frac{\omega \mathrm{L}}{\mathrm{U}_{\mathrm{g} 0}},
$$

with $\tau_{\tau \tau 0}$ being the dimensionless longitudinal stress in the jet inherited from the nozzle. 
On the other hand, at the free end $s=s_{\text {free and }}$ the jet is assumed to be fully unloaded, i.e.,

$$
\xi,\left.\right|_{\text {free end }}=1, \quad H,\left.\left.\right|_{s}\right|_{\text {free end }}=0
$$

The initial condition for Eq. (49) at the moment when a liquid element leaves the nozzle and enters the jet reads

$$
\left.\Phi\right|_{\mathrm{t}=\mathrm{t}_{\text {birth }}}=\left(\tau_{\tau \tau 0}+1 / \mathrm{De}\right) / \lambda_{0}^{2} .
$$

\section{NONLINEAR BEHAVIOR: NONISOTHERMAL CASE}

In the nonisothermal case polymer melt is surrounded by hot gas jet, which is blowing into the space filled with cold gas. As a result, the gas jet is cooled and the encased polymer melt jet is cooled either and solidifies. Following Ref. 2, we assume that the viscosity and relaxation time of polymer melt vary with melt temperature $\mathrm{T}$ according to the following expressions:

$$
\begin{aligned}
\mu= & \mu_{0} \exp \left[\frac{\mathrm{U}}{\mathrm{R}_{\mathrm{g}}}\left(\frac{1}{\mathrm{~T}}-\frac{1}{\mathrm{~T}_{0}}\right)\right], \quad \theta=\theta_{0} \frac{\mathrm{T}_{0}}{\mathrm{~T}} \exp \left[\frac { \mathrm { U } } { \mathrm { R } _ { \mathrm { g } } } \left(\frac{1}{\mathrm{~T}}\right.\right. \\
& \left.\left.-\frac{1}{\mathrm{~T}_{0}}\right)\right],
\end{aligned}
$$

where $\mathrm{T}_{0}$ is the melt and gas jet temperature at the origin, $\mu_{0}$ and $\theta_{0}$ are the corresponding values of the viscosity and relaxation time, $\mathrm{U}$ is the activation energy of viscous flow, and $\mathrm{R}_{\mathrm{g}}$ is the absolute gas constant.

The thermal balance equation for a jet element reads

$$
\frac{\partial}{\partial \mathrm{t}}(\rho \mathrm{cTf} \lambda)=-\mathrm{h}\left(\mathrm{T}-\mathrm{T}_{\mathrm{g}}\right) 2 \pi \mathrm{a} \lambda
$$

where $\mathrm{c}$ is the specific heat, $\mathrm{h}$ is the heat transfer coefficient, and $\mathrm{T}_{\mathrm{g}}$ the local gas temperature.

Using Eq. (33) and rendering temperatures $\mathrm{T}$ and $\mathrm{T}_{\mathrm{g}}$ dimensionless by $\mathrm{T}_{0}$, rearrange Eq. (57) to the following dimensionless form:

$$
\frac{\partial \mathrm{T}}{\partial \mathrm{t}}=-2 \mathrm{Nu} \ell \frac{\mathrm{JC}}{\operatorname{Re}_{\mathrm{a}} \operatorname{Pr}_{\mathrm{g}}} \frac{\lambda}{\lambda_{0}}\left(\mathrm{~T}-\mathrm{T}_{\mathrm{g}}\right),
$$

where $\operatorname{Pr}_{\mathrm{g}}$ is the molecular Prandtl number for gas, C $=c_{p g} / \mathrm{c}$ is the ratio of the specific heat at constant pressure for gas to the specific heat for polymer melt, and the Nusselt number $\mathrm{Nu}=\left(\mathrm{h} 2 \mathrm{a} / \mathrm{k}_{\mathrm{g}}\right)$, with $\mathrm{k}_{\mathrm{g}}$ being the molecular thermal conductivity of gas, is given by the following expression: ${ }^{5}$

$$
\mathrm{Nu}=0.495 \operatorname{Re}_{\mathrm{a}}^{1 / 3} \operatorname{Pr}_{\mathrm{g}}^{1 / 2} \text {. }
$$

Substituting Eqs. (56) into Eq. (40) and using Eq. (58), we obtain the following dimensionless RCE replacing Eq. (49):

$$
\begin{aligned}
\frac{\partial \Phi}{\partial \mathrm{t}}= & -\frac{2 \mathrm{Nu} \ell \mathrm{JC}}{\operatorname{Re}_{\mathrm{a}} \operatorname{Pr}_{\mathrm{g}} \mathrm{De}_{0} \lambda_{0}} \frac{\left(\mathrm{T}-\mathrm{T}_{\mathrm{g}}\right)}{\lambda}-\mathrm{T} \exp \left[-\mathrm{U}_{\mathrm{A}}\left(\frac{1}{\mathrm{~T}}\right.\right. \\
& -1)] \frac{\tau_{\tau \tau}}{\mathrm{De}_{0} \lambda^{2}},
\end{aligned}
$$

with $\Phi=\left(\tau_{\tau \tau}+\mathrm{T} / \mathrm{De}_{0}\right) / \lambda^{2}$ and the following two additional dimensionless groups involved:

$$
\mathrm{De}_{0}=\frac{\theta_{0} \mathrm{U}_{\mathrm{go}}}{\mathrm{L}}, \quad \mathrm{U}_{\mathrm{A}}=\frac{\mathrm{U}}{\mathrm{R}_{\mathrm{g}} \mathrm{T}_{0}} .
$$

Using the theory of the axisymmetric turbulent gas jets, ${ }^{13}$ the temperature field in the gas jet is given by the following expression:

$$
\begin{aligned}
\mathrm{T}_{\mathrm{g}}(\xi, \mathrm{H})= & \mathrm{T}_{\mathrm{g} \infty}+\frac{\left(\mathrm{Pr}_{\mathrm{t}}+1 / 2\right)}{0.05 \sqrt{6}} \frac{\left(1-\mathrm{T}_{\mathrm{g} \infty}\right)}{\ell} \frac{1}{(\xi+4.8 / \ell)} \\
& \times \frac{1}{\left(1+\zeta^{2} / 8\right)^{2 \mathrm{Pr}_{\mathrm{t}}}},
\end{aligned}
$$

where $\mathrm{T}_{\mathrm{g} \infty}$ is the surrounding cold gas temperature far from the polymer jet rendered dimensionless by $\mathrm{T}_{0}$, the turbulent Prandtl number $\operatorname{Pr}_{\mathrm{t}}=0.75$, and $\zeta(\xi, \mathrm{H})$ is given by the second Eq. (46).

It is emphasized that the other governing equations of the problem, e.g., Eqs. (46)-(48) and (50) do not change in the nonisothermal case.

\section{RESULTS AND DISCUSSION}

The governing Eq. (48) is a hyperbolic wave equation for $\xi(\mathrm{s}, \mathrm{t})$, which corresponds to propagation of the elastic compression-expansion waves along the jet (the "elastic sound"). The second governing Eq. (49) responsible for the propagation of the bending perturbations $\mathrm{H}(\mathrm{s}, \mathrm{t})$ is a hyperbolic wave equation if jet is stretched significantly, i.e., $\left[\tau_{\tau \tau} / \mathrm{Re}-\mathrm{J} \varphi^{2}(\xi, \mathrm{H})\right]>0$. If the longitudinal jet stretching would fade due to the elastic relaxation and the distributed lift force $\mathrm{J} \varphi^{2}(\xi, \mathrm{H})$ would become dominating, Eq. (49) changes type and becomes elliptic, since the factor $\left[\tau_{\tau \tau} / \mathrm{Re}\right.$ $\left.-\mathrm{J} \varphi^{2}(\xi, \mathrm{H})\right]$ becomes negative. This behavior has already been mentioned in the linearized version of this problem in Sec. III, which has drastic consequences on perturbation growth.

The following parameter values partially corresponding to those of Ref. 11 were used in the numerical calculations: $\mathrm{a}_{0}=0.2 \mathrm{~cm}, \mathrm{~L}=200 \mathrm{~cm}, \mathrm{U}_{\mathrm{g} 0}=230 \mathrm{~m} / \mathrm{s}, \rho=1 \mathrm{~g} / \mathrm{cm}^{3}, \mu$ $=10^{2} \mathrm{~g} /(\mathrm{cm} \mathrm{s})$, and $\rho_{\mathrm{g}}=1.22 \times 10^{-3} \mathrm{~g} / \mathrm{cm}^{3}$. Therefore, the corresponding values of $\mathrm{Re}, \mathrm{J}$, and $\ell$ were about $\mathrm{Re}$ $=46000, \mathrm{~J}=10^{-3}$, and $\ell=10^{3}$. The effect of gravity was excluded, which corresponds to $\mathrm{Fr}=\infty$. The initial longitudinal elastic stress was taken as $\tau_{\tau \tau 0}=10$ and $\lambda_{0}=1$. The relaxation time was taken about $\theta=0.1 \mathrm{~s}$, which corresponds to De $=10$. In addition, it was taken $\mathrm{C}=0.25$ and $\Omega=0.3$ (the latter corresponds to $\omega=35 \mathrm{~Hz}$; cf. Ref. 1). Also, $\mathrm{T}_{\mathrm{g} \infty}=0.5$ and $\mathrm{U}_{\mathrm{A}}=10$. The value of $\operatorname{Re}_{\mathrm{a}}$ for air $\left(\nu_{\mathrm{g}}=0.15 \mathrm{~cm}^{2} / \mathrm{s}\right)$ is about 46000 . However, at such value of $\operatorname{Re}_{\mathrm{a}}$ the pulling aerodynamic drag described by Eq. (50) is insufficient to initiate meltblowing. This might be related to the fact that the empirical Eq. (50) was established in Ref. 14 in the experiments with threadlines pulled through stagnant air. However, drag imposed by blowing air may be dramatically increased due to the turbulent eddy viscosity (absent in the experiments ${ }^{14}$ ). To account for that fact, the factor 0.65 in Eq. (50) was replaced by 1265 . Then, the aerodynamic drag as per Eq. (50) became quite sufficient to initiate meltblowing.

The implicit numerical scheme of the generalized Crank-Nicolson type with the central difference special dis- 

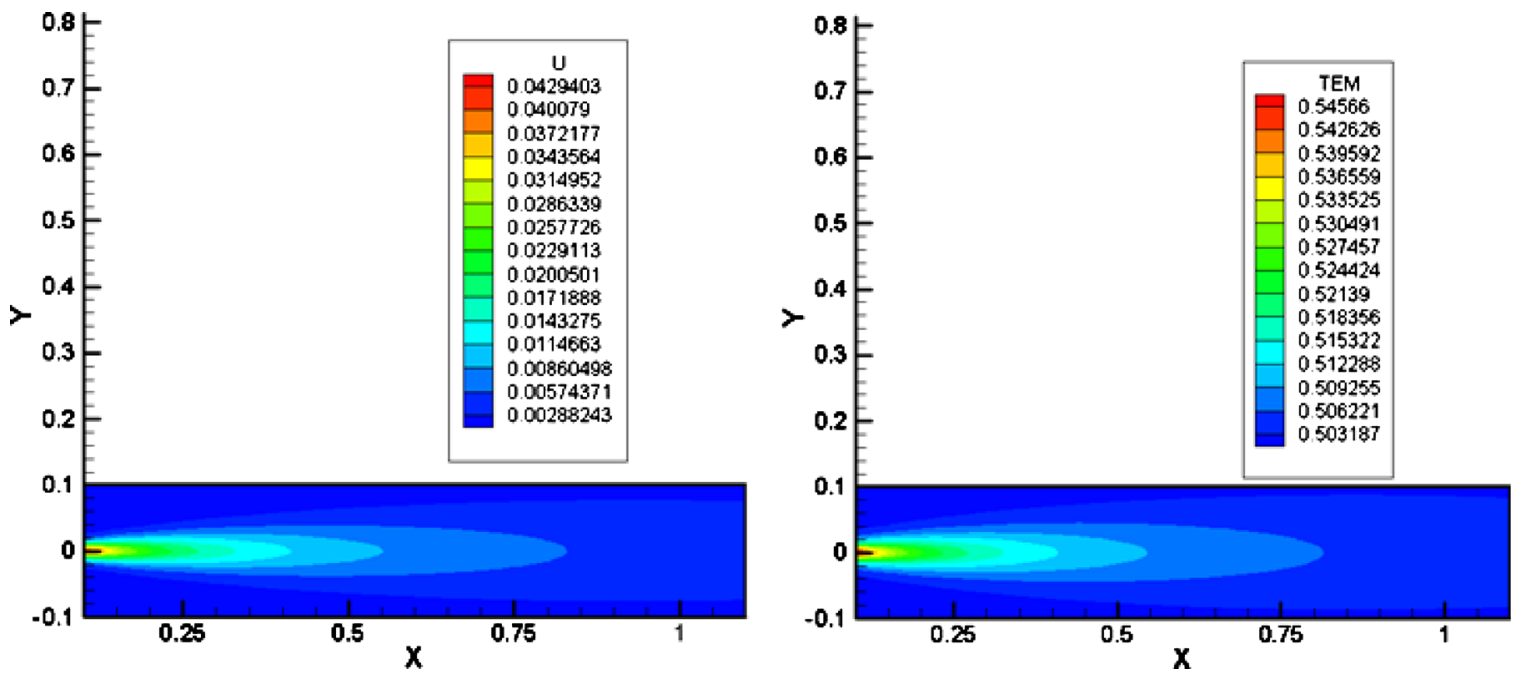

FIG. 5. (Color online) Axisymmetric velocity (left) and temperature (right) fields in the gas jet.

cretisation at three time levels from Ref. 15 (p. 444) was implemented to solve Eqs. (47) and (48) numerically.

The mean axisymmetric velocity and temperature fields in the central domain close to the jet origin calculated using Eqs. (45), (46), and (62) are presented in Fig. 5. Since the turbulent Prandtl number $\operatorname{Pr}_{t}$ is less than $1\left(\operatorname{Pr}_{t}=0.75\right)$, the temperature profile in the gas jet is wider than the velocity profile.

The predicted configurations of the jet axis in the isothermal planar blowing process are depicted in Fig. 6. It is seen that the polymer jet is pulled and strongly stretched by the coflowing gas jet. The polymer jet also experiences lateral perturbations due to turbulent eddies. These bending perturbations are significantly enhanced by the distributed aerodynamic lift force acting on the curved polymer jet. They also propagate along the polymer jet as elastic waves, and are additionally swept by local aerodynamic drag force acting on the jet elements. The configurations of the polymer jet can become rather complicated and self-intersecting in a while [Fig. 6(b)], which is possible for a "phantom" jet but forbidden to a real material one. Still, the evolution similar to that in Fig. 6(b) points at possible self-intersection in meltblowing, even in the case of a single jet considered here.

If one follows individual material Lagrangian elements of the polymer jet, as we do in our calculations, their distribution along the jet allows visualization of a nonuniform jet stretching. Indeed, these material elements are visualized by symbols on the jet axis in Fig. 7. The larger is the distance along the jet between two neighboring symbols, the larger is the local stretching of viscoelastic polymer melt in the corresponding jet section. Figure 7 clearly shows that initially jet stretching is quite significant and growing in time (from snapshot to snapshot in Fig. 7), however, it can deteriorate further on due to the elastic recoil characteristic of viscoelastic polymer melts, as well as a decreasing stretching by the gas jet, which weakens down the flow.

Comparison of Figs. 7(a) and 7(b) allows us to visualize the effect of cooling and solidification of the polymer jet. In particular, it is seen that the growth of the bending perturbations of the jet is arrested similarly to the electrospun jets
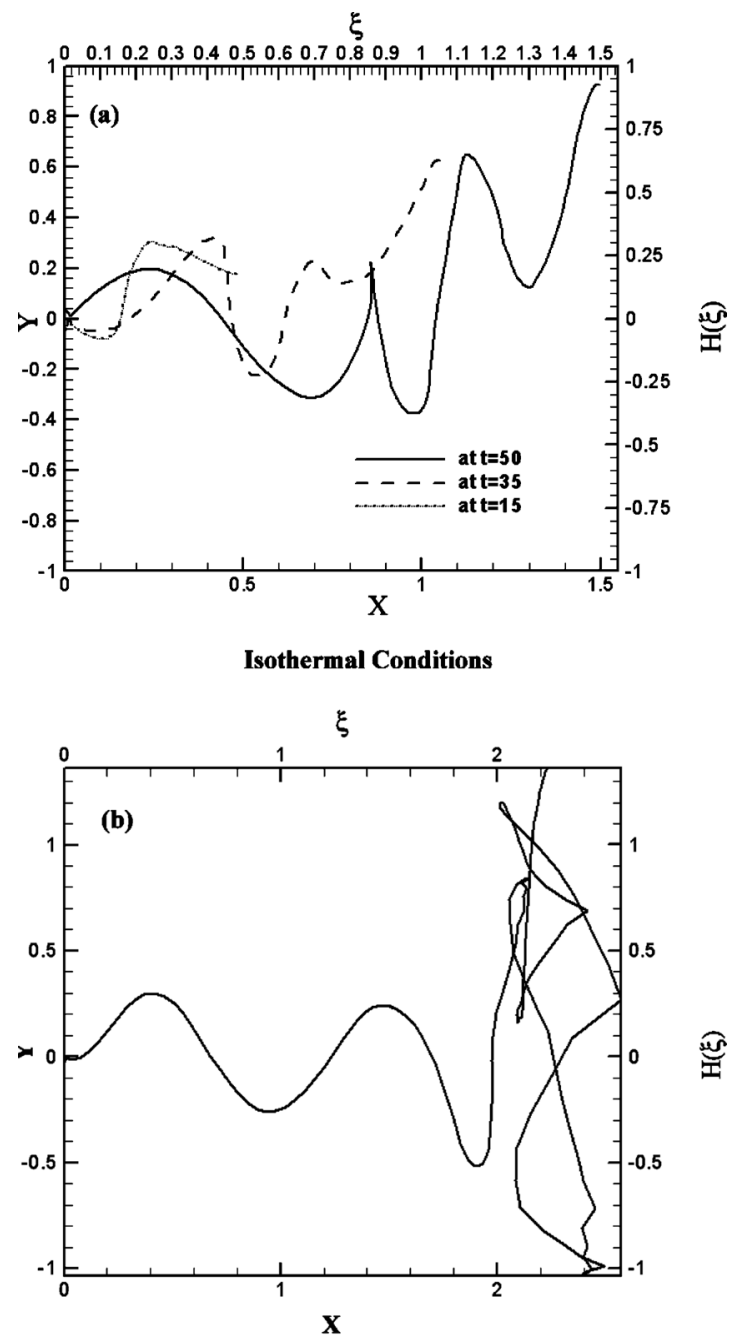

Isothermal Conditions

FIG. 6. Isothermal planar blowing. (a) Three snapshots of the axis configuration of polymer jet at the dimensionless time $\mathrm{t}=15,35$, and 50 (the corresponding dimensional times are $0.13 \mathrm{~s}, 0.3 \mathrm{~s}$, and $0.43 \mathrm{~s}$, respectively). (b) The later snapshot of the polymer jet axis corresponding to the dimensionless time $\mathrm{t}=75$ (the corresponding dimensional time is $0.65 \mathrm{~s}$ ). 


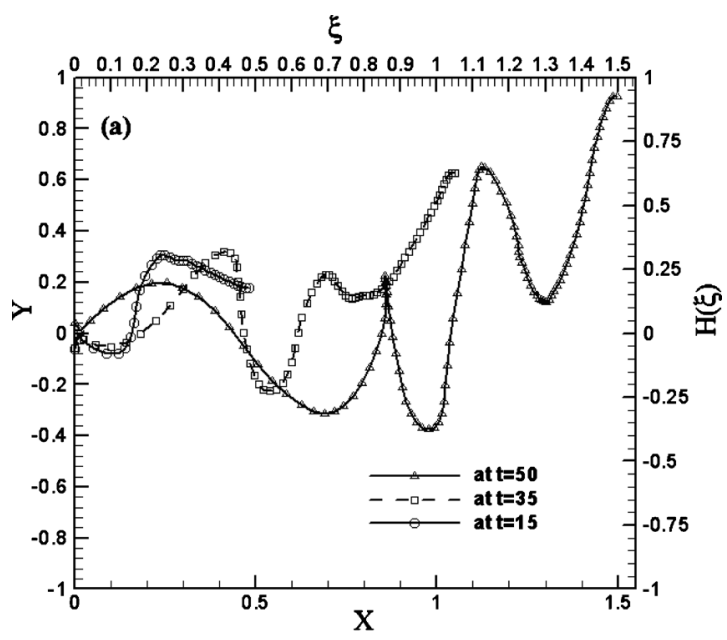

Isothermal Conditions

$\xi$

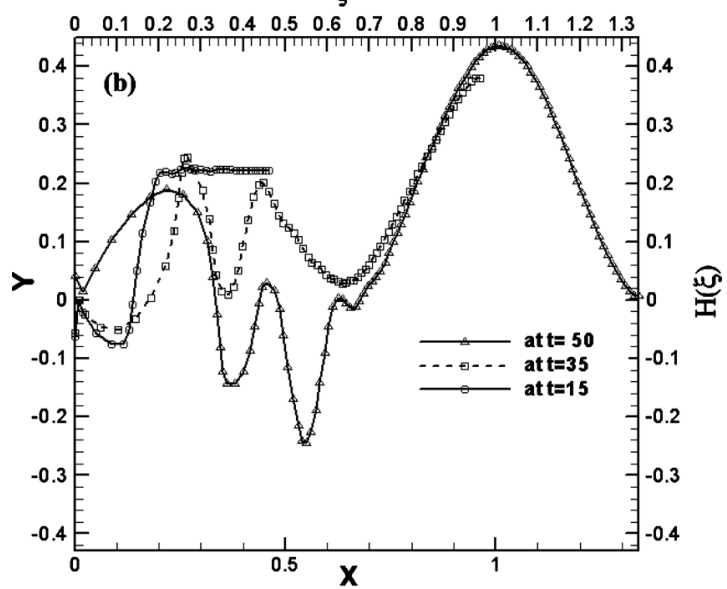

Nonisothermal Conditions

FIG. 7. (a) Three snapshots of the polymer jet axis in the isothermal planar blowing at the dimensionless time $\mathrm{t}=15,35$, and 50 (the corresponding dimensional times are $0.13 \mathrm{~s}, 0.3 \mathrm{~s}$, and $0.43 \mathrm{~s}$, respectively) with the symbols denoting the material elements of the jet. (b) Same in the nonisothermal planar blowing.

described in Ref. 5. However, the jet does not become straight but continues to sustain traveling bending perturbations similarly to the flexible solid threadlines studied in the first paper in this series. ${ }^{1}$

The predictions for the isothermal three-dimensional blowing are shown in Fig. 8. In this case the configuration of the jet axis is described using the following three projections $\xi=\xi(\mathrm{s}), \mathrm{H}=\mathrm{H}(\mathrm{s})$, and $\mathrm{Z}=\mathrm{Z}(\mathrm{s})$ instead of the two, $\xi=\xi(\mathrm{s})$ and $\mathrm{H}=\mathrm{H}(\mathrm{s})$, used in the planar case. The tendency for selfintersection of the polymer jet is clearly seen in the threedimensional case as well.

\section{CONCLUSION}

The linear and nonlinear theory of meltblowing developed in this work explains the physical mechanisms responsible for jet configurations, and in particular the role of the turbulent pulsations in gas jet, of the aerodynamic lift and drag forces, as well of the longitudinal viscoelastic stress in the polymer jet. The theory produces a plausible pattern of

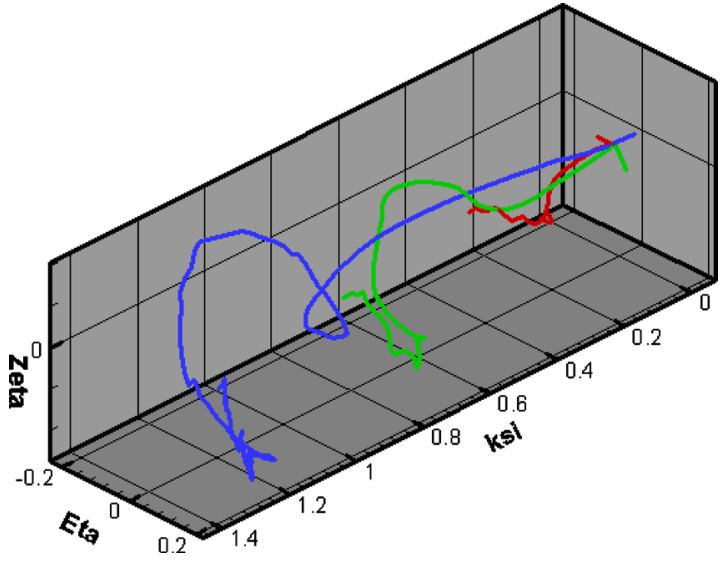

FIG. 8. (Color online) Three snapshots of the polymer jet axis in the isothermal three-dimensional blowing at the dimensional time moments $\mathrm{t}=15$, 30 , and 45 (the corresponding dimensional times are $0.13 \mathrm{~s}, 0.26 \mathrm{~s}$, and 0.39 $\mathrm{s}$, respectively).

the evolution of the jet in time and allows modeling of not only planar but also three-dimensional jets. The current version of the theory deals with a single polymer jet. The further development will proceed toward calculations of multiple jets and their interaction and even merging with each otherthe processes responsible for such defects of meltblown products as roping. Self-intersection of polymer jets visualized by the present results can lead to jet rupture in the case of violent blowing which results in the so-called fly (small jet segments contaminating the surrounding atmosphere). The mechanism of fly formation will also be elucidated by future development of the current model. Formation of the so-called shots resulting from capillary breakup of polymer jets at too high surrounding temperatures will also be targeted after inclusion of capillarity in the model similarly to Ref. 2. A comprehensive model of meltblowing requires simulation of polymer flow in die nosepiece, which will be aimed in the future model development. The last but not least goal is in the prediction of the internal structure in the fibers comprising nonwovens resulting from meltblowing. This information can be elucidated relating the predicted longitudinal stresses "frozen" in the jet at the deposition screen to such characteristic features as crystallininty and ultimately strength.

Finally, we believe that this framework can be used to establish the role of polymer-process interactions on the socalled formation.

\section{ACKNOWLEDGMENTS}

The current work is supported by the Nonwovens Cooperative Research Center (NCRC).

${ }^{1}$ S. Sinha-Ray, A. L. Yarin, and B. Pourdeyhimi, J. Appl. Phys. 108, 034912 (2010).

${ }^{2}$ A. L. Yarin, Free Liquid Jets and Films: Hydrodynamics and Rheology (Longman, Harlow and Wiley, New York, 1993).

${ }^{3}$ V. M. Entov and A. L. Yarin, J. Fluid Mech. 140, 91 (1984).

${ }^{4}$ D. H. Reneker, A. L. Yarin, H. Fong, and S. Koombhongse, J. Appl. Phys. 87, 4531 (2000).

${ }^{5}$ A. L. Yarin, S. Koombhongse, and D. H. Reneker, J. Appl. Phys. 89, 3018 (2001).

${ }^{6}$ D. H. Reneker, A. L. Yarin, E. Zussman, and H. Xu, Adv. Appl. Mech. 41, 
43 (2007).

G. Astarita and G. Marrucci, Principles of Non-Newtonian Fluid Mechanics (McGraw-Hill, London, 1974).

${ }^{8}$ V. M. Entov and K. S. Kestenboim, Fluid Dyn. 22, 677 (1987).

${ }^{9}$ D. D. Joseph, Fluid Dynamics of Viscoelastic Liquids (Springer, Berlin, 1990).

${ }^{10}$ T. Han, A. L. Yarin, and D. H. Reneker, Polymer 49, 1651 (2008).

${ }^{11}$ N. Marheineke and R. Wegener, SIAM J. Appl. Math. 68, 1 (2007).
${ }^{12}$ G. N. Abramovich, The Theory of Turbulent Jets (MIT, Boston, 1963).

${ }^{13}$ A. L. Yarin, in Springer Handbook of Experimental Fluid Mechanics, edited by C. Tropea, A. L. Yarin, and J. Foss (Springer, Berlin, 2007), pp. 57-82.

${ }^{14}$ High-Speed Fiber Spinning, edited by A. Ziabicki and H. Kawai (Wiley, New York, 1985).

${ }^{15}$ R. M. M. Mattheij, S. W. Rienstra, and J. H. M. ten Thije Boonkkamp, Partial Differential Equations (SIAM, Philadelphia, 2005). 